\title{
Power Management in Solar PV - Microhydro Hybrid System Using Power Angle Control Strategy with Syncronverter
}

Deependra Neupane ( $\boldsymbol{\nabla}$ deependra@ioepc.edu.np)

Tribhuvan University Institute of Engineering Purwanchal Campus https://orcid.org/0000-0002-30920372

Samundra Gurung

Kathmandu University

\section{Research Article}

Keywords: syncronverter, microhydro SPV hybrid-system, distributed-generation, load-frequency control

Posted Date: January 19th, 2022

DOl: https://doi.org/10.21203/rs.3.rs-1248332/v1

License: (c) (i) This work is licensed under a Creative Commons Attribution 4.0 International License.

Read Full License 


\title{
Power Management in Solar PV - Microhydro Hybrid System Using Power Angle Control Strategy with Syncronverter
}

\author{
Deependra Neupane ${ }^{\mathrm{a}, *}$, Samundra Gurung ${ }^{\mathrm{b}}$ \\ ${ }^{a}$ Department of Electrical Engineering, Purwanchal Campus, Institute of Engineering, Tribhuvan University, Gangalal Marg, \\ Dharan, 56700, Sunsari District, Province No. 1, Nepal \\ ${ }^{b}$ Department of Electrical and Electronics Engineering, Kathmandu University, Dhulikhel, Bagmati Province, Nepal
}

\begin{abstract}
The most crucial control challenge in the hybrid-system is the frequency stability, especially when they are in the face of load-generation imbalance and numerous uncertainties. In this paper, the Syncronverter (SV) based on a micro hydropower System (MHPS) is proposed to handle the intermittent power output of Solar Photo-voltaic (SPV). The standalone microgrid is modeled in the MATLAB/Simulink environment. The power control form SV is performed using Power Angle Control(PAC) method. Several case studies are performed, and the simulation results show the dynamics of appropriate sharing of power for both the linear and nonlinear loads by the hybrid system. Both the frequency and Total Harmonic Distortion (THD) of load voltage kept within the standard limits. The application of SV shows a quick and smooth synchronization with micro-hydro. The change in irradiance level has been appropriately managed by power-sharing with micro-hydro to save the system from frequency imbalance during low light conditions. The power has been shared by providing an appropriate load angle between sources based on the irradiance level available at the time. Moreover, the dynamic response of voltage, power, and frequency of the system due to the induction motor load has also been studied.

Keywords: syncronverter, microhydro SPV hybrid-system, distributed-generation, load-frequency control
\end{abstract}

\section{Introduction}

The process of developing technology to use renewable energy sources at a small scale that is cheap and can meet the needs of people is still emerging and developing [1]. Among all renewable sources, Solar Photovoltaic (SPV) systems-based hybrid systems and distributed generations are getting more attraction worldwide [2]. SPV possesses a simple design, long operation life, and does not produce any further pollution during energy provision [3]. Similarly, MicroHydro Power (MHP) based distributed generations has been an

\footnotetext{
${ }^{*}$ Corresponding author

Email address: deependra@ioepc.edu.np (Deependra Neupane)
} 
excellent solution for the areas with adequate water flow. MHP is simple in construction, easily operatable, clean, cost-effective, and generates an almost constant electrical supply. Therefore, MHP technology can be considered for the source electrification for rural areas in less developed countries [4]. Moreover, renewable resources possess their own merits and demerits in their application for power generation.

Despite its popularity, solar power sources possess significant power drawbacks generation uncertainty as the power from the solar resource is environmentally dependent. Moreover, in an isolated SPV system, the power fluctuation results in frequency deviation(or requires complex circuitry and control system to balance the frequency and load) in the design and has less reliable performance.

Similarly, a significant drawback of load-frequency imbalance and poor reliability due to overloading has discouraged the isolated MHP in rural areas. [5, 6]. This has resulted in reducing the life of the system and ultimately shutting down the plant. Moreover, in Electronic Load Controller(ELC) based micro-hydro system, the generator has to be supplied with rated discharge throughout the time that causes a substantial loss of power in a dummy load.

The hybrid systems have turned into one of the most promising ways to satisfy the electrification requirements of rural areas[7, 8]. Hybrid energy systems with renewable energy resources are more encouraged as they have a much lower environmental impact than the systems with conventional energy resources. Moreover, a renewable energy source (RES) based hybrid system additionally reduces the possibility of source-load imbalance due to the environmental dependency of renewable resources on power generation. Among several RES-based hybrid systems, solar and MHP hybrid systems can solve the deformities of both systems, SPV and MHP, as discussed earlier, in terms of frequency imbalance and power losses.

Hence, Thus an SPV system consisting of an SPV array with converters, harmonic filters, and an MHP plant consisting of hydraulic turbines, a synchronous generator, and an electronic load controller is integrated into a solar micro-hydro hybrid power system (SMHPS). The efficiency and reliability of the SMHPS mainly depend upon the control strategy of the converter on the SPV side and the load controller on the MH side. Since the nature and performance of SPV is quite different in terms of physical and electrical characteristics than that of synchronous generators used in MHP, SPV penetration affects the frequency stability of the system [9]. Moreover, using power electronics-based devices like voltage source converters and electronic load controllers creates voltage and current distortion in the system.

Due to several advantages of SV as a converter, such as availability of voltage and frequency droop mechanism [10], it provides greater flexibility on its application on microgrids. Moreover, SV has more considerable inertia than conventional inverter droop control and therefore provides better frequency stability in the system [11]. Furthermore, the inherent inertial characteristic of the SV can provide services as frequency support and transient power-sharing as primary control actions[12]. Similarly, an SV-based power converter operates as a voltage source connected to the grid. Therefore, it can supply fault currents, as well 
as unbalanced and harmonic currents to nonlinear loads [13]. Moreover, SV based system can reduce the rate of change of frequency in the system that has a high penetration of variable renewable energy generation sources [13] and possess automatic synchronization ability[14, 15].

Several studies have used the SV as a medium for the renewable source to integrate into the grid or microgrid. Amin and colleagues have presented the method of reference power variation in the syncronverter based on source voltage fluctuation using a PI controller [16]. Similarly, Chandrakar and friends have studied the grid integration of solar PV using a syncronverter [17]. Apart from these, Meshram et al. has examined the solar and micro-hydro using induction machine as a micro hydropower source [18]. Cvetkovic and colleagues have studied the average model of the SV-based grid-interface converters for renewable energy systems integration [19]. Ralf and colleagues have studied the ability of SV to let renewable-based energy systems be interconnected on the grid with reduced disturbances [20]. Hirase and friends have studies on the application of virtual synchronous generators to provide frequency control support for the system [21]. Sarhan and friends have suggested a control method of such systems based on direct control of power angle between SV voltage and grid voltage, termed as power angle control [22].

This study has introduced the power-sharing of SV-based SPV with an MHP hybrid system using the power angle variation method in the SV. Hence, this study presents a theoretical basis of a hybrid system using synchronous machines in MHP and SPV in SV as a power source. The modeling and simulation are carried out under MATLAB/SIMULINK environment using simscape libraries. The effect of load variations, source variation (irradiance level in SPV) on voltage profile, harmonics, and sharing proportion has been studied. Similarly, the effect of induction motors as the load on the proposed hybrid system is analyzed.

\section{Component Modelling}

\subsection{Modelling of Synchronverter}

VSM is an inverter that can be operated to imitate the behavior of a synchronous generator (SG). The dynamic equations of both systems are similar. However, the mechanical power exchanged with the prime mover, in the case of SG, is replaced with the power exchanged with the dc bus in the case of SV [23]. In this study, the SV model suggested by Zhong [24] has been implemented. The SV model is shown in Figure 1 that shows electronic, power, and dc sources. The dc source here, in our case, is SPV with a capacitor. The capacitor is used for short power supply during power transients. Moreover, a filter is needed as the interface between the inverter and the MHP to provide smooth current injection. Compared with the L filter, the LCL filter is considered a preferred choice for its cost-effective attenuation of switching frequency harmonics in the injected grid currents [25]. Hence, the LCL filter has been modeled, and the parameter is calculated based on a study performed by Ruan and colleagues [25]. While integrating syncronverters with other sources, synchronization is an important phenomenon. Phase-Locked Loop (PLL) is used among 
various synchronization techniques to synchronize the SV to MHP in this study. PLL is a well-known, and widely used control technique for three-phase power systems is synchronous reference frame Phase Locked Loop (PLL) [26].

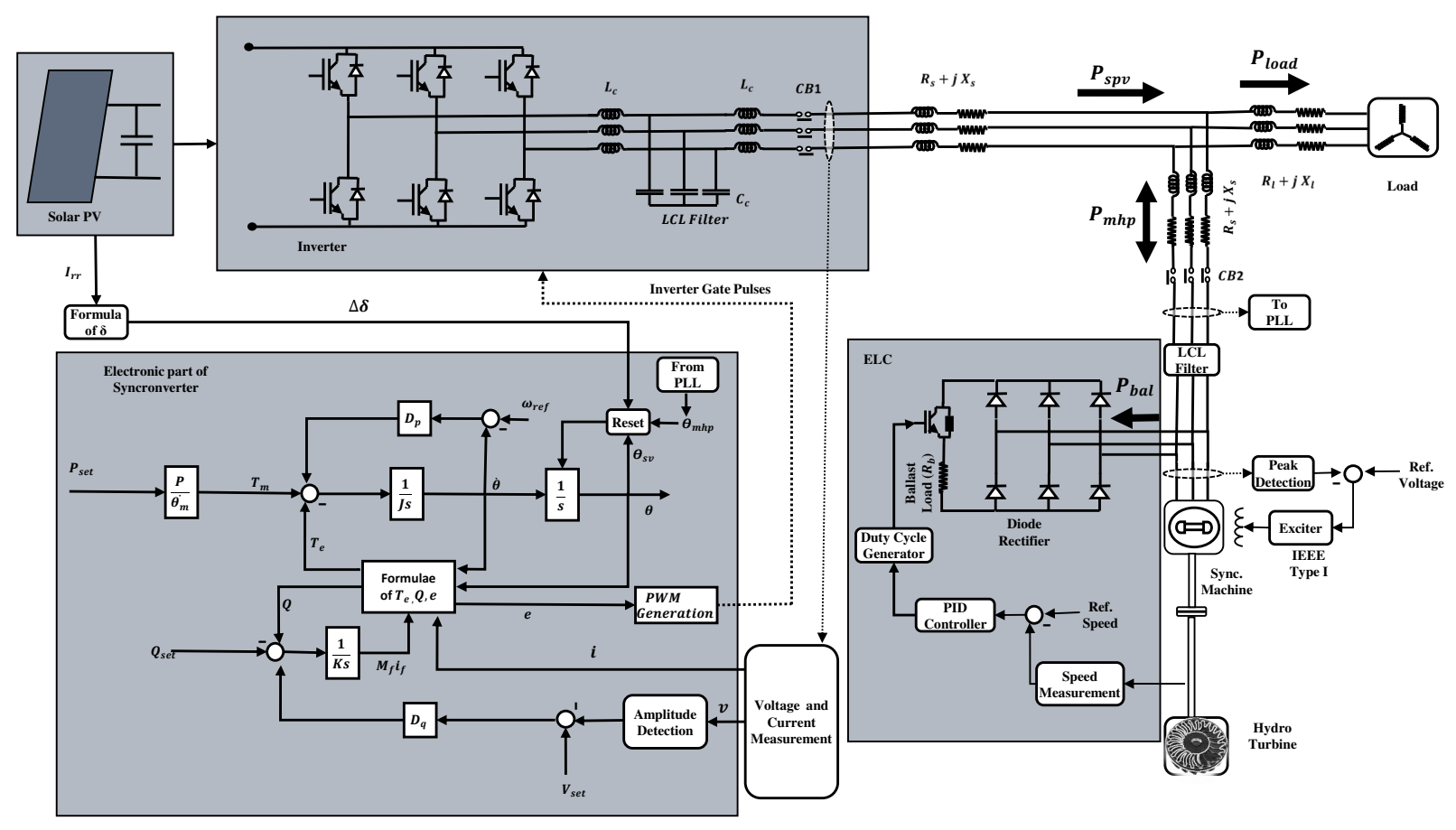

Figure 1: The detailed model of the proposed hybrid system. The system constitutes the SV model (both power and electronic), MHP with ELC, SPV, load, and common three-phase interconnecting line. The model of SV here has been adapted from work done by Zhong and colleagues [24].

The modelling of SV is based on the mathematical equations where equations for voltage signal and power are shown below:

$$
\begin{gathered}
e=\dot{\theta} M_{f} i_{f} \sin \theta \\
P=\dot{\theta} M_{f} i_{f}\langle i, \tilde{\sin } \theta\rangle \\
Q=-\dot{\theta} M_{f} i_{f}\langle i, \tilde{\cos } \theta\rangle
\end{gathered}
$$

Where e is the three-phase reference signal given to the pulse width modulation (PWM) generator, and $\mathrm{P}$ is the electrical power developed by the SV. $M_{f}$ and $i_{f}$ are the maximum mutual inductance between the stator winding and the field winding and field excitation current. Similarly, $i$ is the stator phasor current in three-phase. The phasor matrix can be given by equation (4).

$$
\tilde{\sin } \theta=\left[\sin \theta \quad \sin \left(\theta-\frac{2 \pi}{3}\right) \quad \sin \left(\theta+\frac{2 \pi}{3}\right)\right]
$$


The rotor dynamic equation that is imitated by the SV is given as:

$$
\ddot{\theta}=\frac{1}{J}\left(T_{m}-T_{e}-D_{p} \dot{\theta}\right)
$$

Where $\mathrm{J}$ is the virtual inertia of the SV, $T_{m}$ is the fictitious mechanical torque developed, $T_{e}$ is the electrical power developed and $D_{p}$ is the droop regulation parameter. Similarly, $\theta$ is the virtual power angle of the SV, which can be artificially regulated or reset using signal processes while synchronization and power-sharing. Finally, the peak voltage is calculated using equation (6).

$$
v_{f b}=\frac{2}{\sqrt{3}} \sqrt{-\left(v_{a} v_{b}+v_{b} v_{c}+v_{c} v_{a}\right)}
$$

Where $v_{a}, v_{b}$ and $v_{c}$ are line voltages measured by voltage sensors. The parameters used in the analysis have been approximated and calculated based on the study performed by Zhong [23]. The equation has been solved using the MATLAB/SIMULINK function block. The reference signal generated is compared with a triangular pulse signal of $5 \mathrm{kHz}$ frequency to generate gate pulses for the switching circuit of the inverter.

\subsection{Modelling Solar PV}

The mathematical model for the simplified equivalent circuit of solar PV is adapted from the study done by Allani and colleagues [27]. The model is used for the real and practical case as shown in figure 2 (a). The relationship between current and voltage in solar PV is given in equation 7. The PV Array block uses a five-parameter model using a light-generated current source (IL), diode, series resistance (Rs), and shunt resistance (Rsh) to represent the irradiance- and temperature-dependent I-V characteristics of the modules. A $10.66 \mathrm{~kW}$ rating of solar PV using the preset 1STH-215P PV module model from the National Renewable Energy Laboratory (NREL) System Advisor Model (2018) has been used in the simulation. The I-V and $\mathrm{P}-\mathrm{V}$ characteristics of the solar PV used in the simulation are shown in Figure 2 (b).

$$
I=I_{L}-I_{s}\left[\exp \left(\frac{q \times(V+I) \times R_{s}}{A \times k \times T}\right)-1\right]-\left(\frac{V+I \times R_{s}}{R_{s h}}\right)
$$

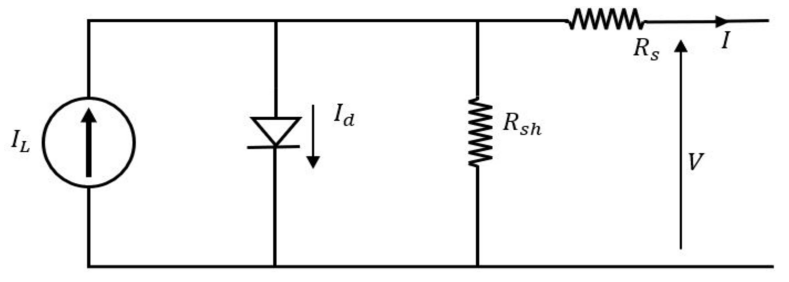

(a)

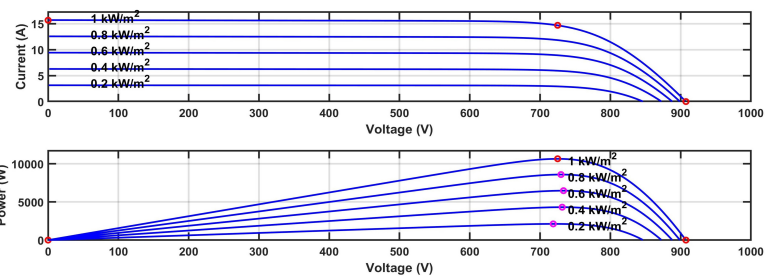

(b)

Figure 2: Load sharing and voltage profile for different irradiance level in SPV. 


\subsection{Modelling MHP}

The MHP model has been realized using the mathematical models of major components such as hydraulic turbines, generators, excitation systems, and electronic load controllers. As the SG in grid-connected or isolated MHP system provides more significant advantages and flexibility compared to the induction machine[28], SG has been used as a generator in MHP. Synchronous generators can run isolated from the grid, and they can produce power since excitation is grid-independent [29]. Moreover, highly efficient synchronous generators have an inbuilt Automatic Voltage Regulator (AVR) for voltage regulation. Additionally, SG with ELC can achieve good frequency regulation. Among the several models of synchronous machine, the IEEE standard 1110-2002 [30] using the preset model of SimPower systems library of Simulink [31] has been used in the simulation. The preset is $8.1 \mathrm{kVA}, 6.5 \mathrm{~kW}, 50 \mathrm{~Hz}, 1500 \mathrm{rpm}, 400 \mathrm{~V}$ salient pole. The voltage regulator-exciter for the SG is an IEEE type 1 model [32]. A constant reference voltage of 1 per unit(400 V) is given as a reference voltage signal for the excitation system. Similarly, the hydraulic turbine block implements a nonlinear hydraulic turbine model as described in [33].

In this study, an Electronic load converter is realized using a three-phase diode bridge rectifier to provide dc power regulation for ballast load. Speed regulation control strategy is obtained by taking the speed error and providing an appropriate duty cycle through Proportionate, Integral, and Derivative (PID) controller to Pulse Width Modulation (PWM) generator. The PWM generator would turn on the transistor for the duty cycle to regulate the power transfer ballast resistor. The load variation will compensate by the loading in the ballast load. The model has been adapted from the study done by Rai and colleagues [34] and shown in the ELC section of figure 1. Sinusoidal voltage waveforms are chopped when the transistor is turned off. Due to chopping, the dump load through the resistive draws a lagging current. The synchronous generator provides the reactive power demanded by the dump load. An appropriate LCL filter circuit has been provided to reduce the voltage harmonics. The parameters for the LCL filter for harmonic reduction and smooth current injection are calculated based on the study done by ruan and friends [25].

\subsection{Load Modelling}

Generally, the electricity consumption in rural areas is contributed by lighting and milling requirements. Hence, this study has considered two loading conditions. We have used the balanced variable three-phase resistive load to mimic the lighting load in one situation. While, in another case, we have implemented induction motor load to represent the milling load requirement. The load is assumed to draw only the active load during the resistive and partially reactive loads during the induction motor. The resistive load has been varied by connecting several resistive load blocks at different simulation times. Similarly, load torque has been changed at other simulation times for induction motor load. For induction motor load, a model of squirrel case induction motor from SimPower library of Simulink of rating 4 kW,400 V, 1430 RPM has been used in the study. 


\section{Load Sharing and Control}

The power transfer from SV and MHP can be done by controlling the load angle $(\delta)$ between the inverter and MHP. The load sharing and control operation is performed using the technique of power angle control(PAC) method adapted from several works of literature [35, 36, 37, 22]. Moreover, the maximum power from the SPV can also be extracted using the phase angle control [38]. This removes implementing the Maximum Power Point Tracking (MPPT) algorithm in the system. Initially, the solar and MHP are synchronized at a certain time by obtaining the phase angle of MHP output voltage $\theta_{g}$ via. Phase lock loop (PLL) control system. The power-sharing mechanism is performed by varying the power angle $(\delta)$ between the MHP and inverter output voltages. During synchronisation, the inverter voltage $\theta$ is reset to $\theta_{g}-\delta$. This will result in the power transfer from the syncronverter to the MHP to be:

$$
\begin{gathered}
P=\frac{V_{i n v} V_{m h p}}{X} \sin \left(\delta_{i n v}-\delta_{m h p}\right) \\
=\frac{V_{i n v} V_{m h p}}{X} \sin \left(\theta-\theta_{m h p}\right) \approx \frac{V^{2}}{X} \sin (\Delta \delta)
\end{gathered}
$$

Where, $\theta_{m h p}=\omega_{m h p} t$ is the measured by PLL and $V_{i n v}$ and $V_{m} h p$ are the syncronverter and micro-hydro voltages. The power flow between the converter and MHP is controlled by resetting the $\theta$ angle of the VSM as shown in the detailed figure, with the following angle defined by the droop equation. Using the power and droop control equation [39]. The change in power angle to share power between SPV and MHP can be written as follows:

$$
\Delta \delta=\beta \times\left(P-P_{\text {rated }}\right)
$$

Where, $\mathrm{P}$ is the power set which is proportional to the irridance level of the solar PV. Hence, the equation can be rewritten as:

$$
\Delta \delta=\beta \times\left(n \times I_{r r}-P_{\text {rated }}\right)=\alpha \times I_{r r}-\beta \times P_{s v, \text { rated }}
$$

Where $\alpha$ and $\beta$ depend on the rating of the Solar PV panel, and $I_{r r}$ is the irradiance level. $P_{\text {rated }}$ is the maximum power that can be generated by solar PV at $1000 \mathrm{~W} / \mathrm{m}^{2}$ irradiance level. The constant $\delta$ angle maintained between the SV and MHP as per the irradiance level will result in the power flow from SPV to MHP similar to load sharing that of a parallel synchronous machine. During isolated MHP operation conditions, all load is handled by MHP. The dynamic load variation is dealt with by ELC. Load sharing is predominantly by solar PV during day conditions, and only during the excess power need condition will the MHP share the appropriate load. 


\section{Simulation and Results:}

A proposed hybrid system shown in figure 1 was implemented in Matlab/Simulink 2018b platform with Simscape Electrical to demonstrate the effective power-sharing between the sources. The simulation is performed using an ode23tb(stiff/TR-BDF2) solver with a step size of 1e-6. The circuit breaker on the syncronverter side is used to disconnect the inverter system when the irradiance level is too low to protect the system from a reverse power supply. Similarly, a circuit breaker on the MHP side is used for initial synchronization in the simulation process. The signal in the circuit breaker is made to operate to disconnect when the irradiance level is too low (less than $100 \mathrm{w} / \mathrm{m} 2$ used in the study). The breaker will be instantly closed when the irradiance level rises. The re-closing of the circuit breaker does not affect the re-synchronization as the inverter output voltage is reset in every sampling time with the value calculated using equation 10 . Voltage and current measurement blocks are used to measure the instantaneous voltage and current at the source terminals. The active power has been calculated using the measured instantaneous voltage and current. Since the ballast load lies under the MHP block, during the low loading condition, when the SV can only supply the load, the ballast load has to consume the excess power from the solar PV with sum to the rated capacity of MHP(from the electronic load converter). The overall model layout for the hybrid system is shown in Figure 1. Before synchronization with MHP, SV virtual angle $(\theta)$ is reset to the reference voltage angle of MHP measured by PLL with added load angle as explained in section 3 at simulation time of 0.35 sec that causes a small voltage, current, and frequency distortion in the system at the time. The actual power generated by the syncronverter will be the sum of losses in the line and power shared to load and the excess energy lost in the ballast load. As the measurement block for the SV side is kept after the line, the actual power generated by the SV is the sum of total line losses from SV and the measured value. The Total Harmonic Distortion (THD) of the load current and voltage has been measured.

The value of parameters used in the simulation is shown in Table 1:

Table 1: Parameters of modelled hybrid system used in the simulation

\begin{tabular}{llllll}
\hline Parameter & Value & Parameter & Value & Parameter & Value \\
\hline Rated Voltage (base V), $V_{s}$ & $400 \mathrm{~V}$ & SV Reactive power droop gain, $\mathrm{K}$ & 500 & Filter Inductance, $L_{s}$ & $10 \mathrm{mH}$ \\
Rated Inverter power, $S_{i}$ & $12 \mathrm{kVA}$ & Rated solar pv, $P_{P V}$ & $10.01 \mathrm{~kW}$ & Filter Capacitence, $C_{s}$ & $0.5 \mathrm{uF}$ \\
Switching Frequency, $f_{s}$ & $5 \mathrm{kHz}$ & Voltage Reference, $V_{\text {ref }}$ & $1 \mathrm{pu}$ & Line Resistance, $R_{g}$ & $1 \Omega$ \\
SV Inertial Constant, J & 2 & Speed Reference, $\omega_{\text {ref }}$ & $1 \mathrm{pu}$ & Line Inductance, $L_{g}$ & $0.025 \mathrm{H}$ \\
SV Damping Coefficent, D & 636 & Turbine Gain, k & $1 \mathrm{pu}$ & Ballast Load Resistance, $R_{b}$ & $10 \Omega$ \\
SV Voltage Droop Coefficent, K & 0.6437 & Water Time constant, $T_{w}$ & $1 \mathrm{sec}$ & Alternator Rating $($ Base $\mathrm{kVA}), S_{A}$ & $8.1 \mathrm{kVA}$ \\
Reference Power, $P_{r e f}$ & $1 \mathrm{pu}$ & Turbine Damping Coefficient, $\beta_{t}$, & $1 \mathrm{pu}$ & System Frequency, $\mathrm{f}$ & $50 \mathrm{~Hz}$ \\
PV source capacitance, $C_{P V}$ & $500 \mathrm{uF}$ & PV source Resistance & $0.5 \Omega$ & Solar DC Max Voltage, $V_{P V}$ & $900 \mathrm{~V}$ \\
Exciter Gain, $K_{e}$ & 300 & Exciter Time Constant, $T_{e}$ & 0.001 & Sample time $T_{s}$ & $1 \mathrm{us}$ \\
$\delta$ Control Parameter, $\alpha$ & -0.0322 & $\delta$ Control Parameter, $\beta$ & $-2.22 \times 10^{-4}$ & Maximum Power SV, $P_{\text {max }}$ & $10.01 \mathrm{~kW}$ \\
ELC Proportionate gain, P & 50 & ELC Integral gain, I & 100 & ElC Derivative gain, D & 0.05 \\
\hline
\end{tabular}




\subsection{Standalone MHP System}

The standalone MHP system consisting of ELC, SG, Excitation system, hydraulic system with loading is simulated to verify the SG system with ELC model. Figure 3 (a) shows the power supplied by MHP to load and ballast power. The ELC has provided appropriate load sharing to maintain the system frequency shown in figure 3 (b). The system's frequency seems to be oscillating for a short period during the change in load. The load voltage is slightly below the source or MHP due to the line resistance and reactance. The voltage of the load is decreasing with an increasing load which is shown in 4 (b). The total harmonic distortion of the system is below five \%, as can be seen in figure 4 (a) besides the condition of transient where the level is THD is too high.

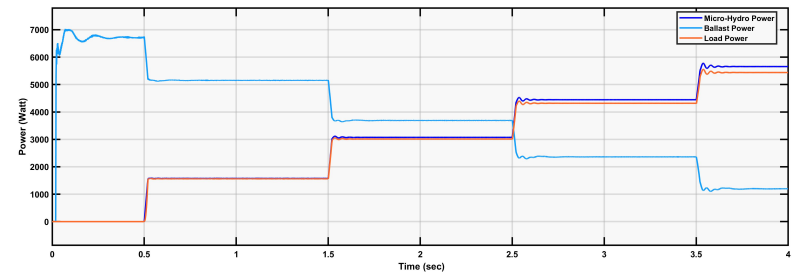

(a)

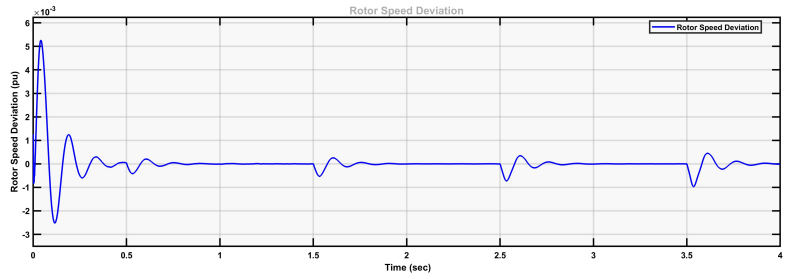

(b)

Figure 3: Load sharing and voltage profile for different irradiance level in SPV.

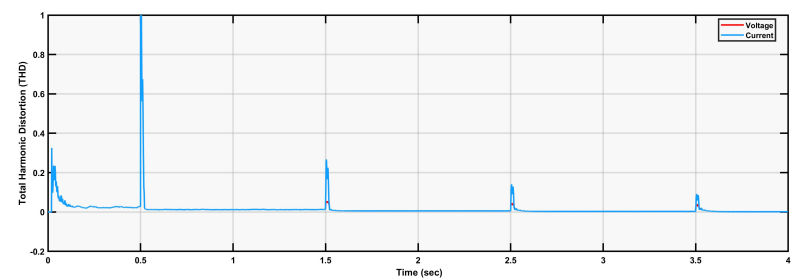

(a)

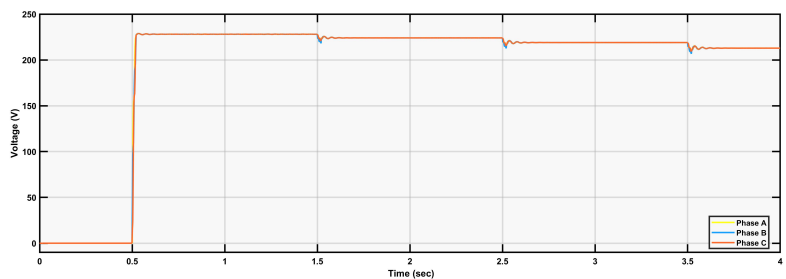

(b)

Figure 4: System frequency and Total Harmonic Distortion (THD) profile in load.

\subsection{Solar-MHP Hybrid System}

\subsubsection{Constant Irradiance Condition:}

The simulation is carried out for constant irradiance conditions of $1000 \mathrm{~W} / \mathrm{m} 2$, and the load in the system is varied. The load sharing with different loading conditions is shown in the figure 5 (a). Initially, under loading conditions, and even when the MHP is not synchronized, the load is supplied by SV only. The excess power from the MHP is dissipated in the ballast load. After synchronization, the excess energy generated from SV and MHP dissipates to ballast load. The ballast load combined dissipated MHP power and extra SPV power. When the load is increased, the loading is proportionally shared by both sources. The SV shares the load until it reaches its rated supply. After a simulation time of 3 seconds, the solar output 
becomes constant irrelevant to the load increment. After that, MHP will share the load. However, due to the high load and excess current in the line, voltage drop becomes significant that can be seen in figure 5 (b). This results in low load power consumption even load is connected. The simulation has shown that the syncronverter automatically adjusts its power output according to the power requirements. The excess power from the syncronverter and MHP cumulatively dissipates into ballast load for low load conditions. This is why the ballast load possesses lots of harmonics in light load conditions and smooth power losses in high load conditions, as can be seen in figure 6 (b). The voltage drop in the load side results in a drop in load power for higher loading conditions though the resistive load parameter is increased. An appropriate voltage regulation device has to be used to minimize this problem. Moreover, the excitation can be increased by remotely measuring the load voltage or adjusting the syncronverter reactive power setting. Sinusoidal voltage and current waveform of load with THD $1.2 \%$ has been obtained, which is less than the $5 \%$ limit imposed by IEEE519 standard[40] except during synchronization step load change. The system frequency has not changed by more than $\pm 0.5 \%$ as can be seen in figure 6 (a). A slight oscillation can be observed during the initial load angle reset, synchronization, and step load variation.
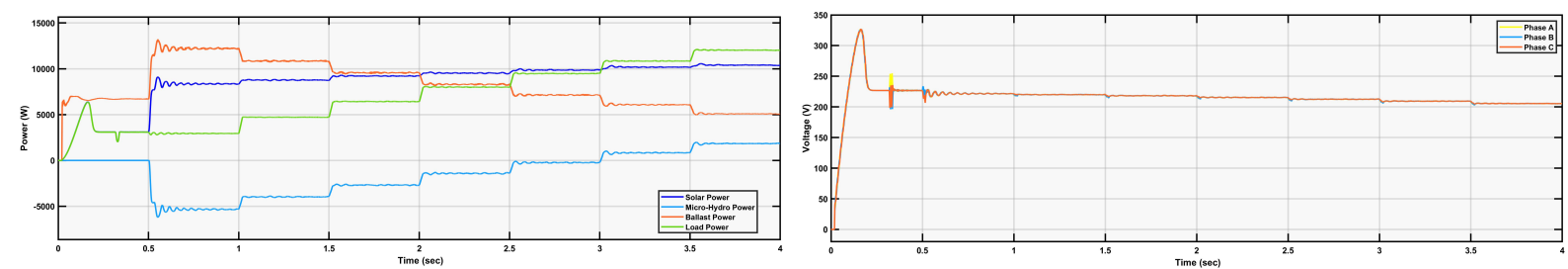

Figure 5: Load sharing and voltage profile for different loading level.
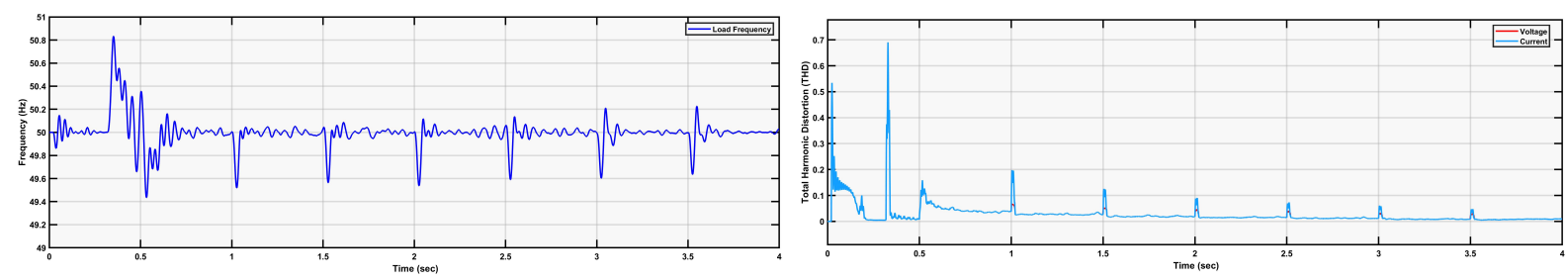

Figure 6: Frequency and Total Harmonic Distortion (THD) profile of the load side.

\subsubsection{Effect of Irradiance:}

The system is highly affected by the solar irradiance level, which is unpredictable even in the daytime. Hence, the irradiance level is varied to observe the load sharing mechanism in the hybrid system. The irradiance level is reduced from $1000 \mathrm{~W} / \mathrm{m} 2$ linearly to $0 \mathrm{~W} / \mathrm{m} 2$ from simulation time 1 to 3 seconds. The irradiance again increased linearly after simulation time 3 . The load is made constant to $3200 \mathrm{~W}$ for all simulation time. As the irradiance level becomes low, the output power from the inverter becomes low, which results in taking the load by MHP as can be seen in figure 7 (a). Initially, the load is accepted by 
the syncronverter. After synchronization, the excess power from SPV and MHPis dissipated in the ballast load. As the irradiance level becomes low, the output power from the syncronverter becomes low, which results in MHP sharing the load to meet the demand. Therefore, during low light or night conditions, the power is solely supplied by MHP. Thus, appropriate scheduling and load shifting have to be done to improve the capacity factor of the hybrid system. The voltage profile has shown a slight oscillation during synchronization but remains constant throughout the simulation time. Hence, the sharing has not affected the voltage regulation of the system, as can be seen in figure 7 (b). Similarly, the frequency deviation is within the limit of $\pm 0.5 \%$, ignoring the condition during synchronization 8 (a). When the irradiance level is too low, we have taken $100 \mathrm{~W} / \mathrm{m}^{2}$, and the SV side gets disconnected from the MHP. This would protect the system from reverse power flow. One of the advantages of using the SV is when the irradiance level is increased that results from the re-close of the circuit breaker, the system will instantly synchronize with the system. During the disconnection of SV, MHP alone has to supply for the whole load that caused the high current to flow and results in a slight voltage drop in the load, which can be mitigated by using appropriate var compensating devices at the load end. The sinusoidal voltage and current waveform with THD 1.3\% have been obtained, which is less than $5 \%$ limits as mentioned earlier except transient condition as depicted in figure 8 (b).
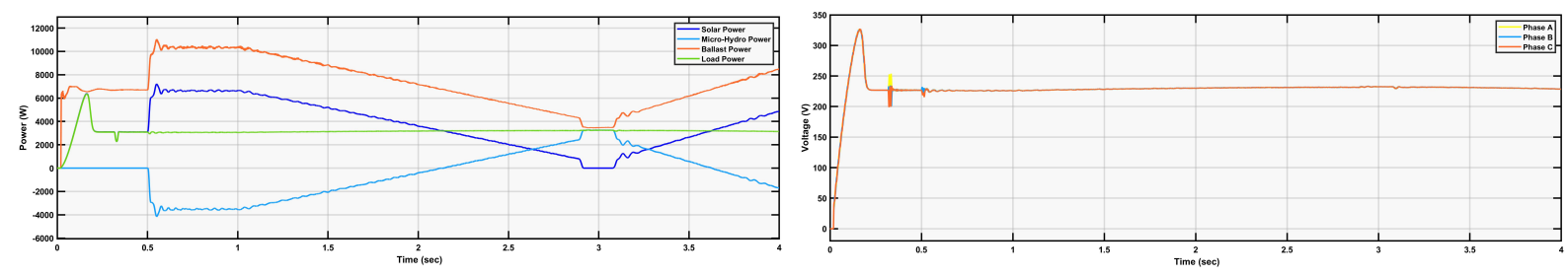

Figure 7: Load sharing and voltage profile for different irradiance level in SPV.
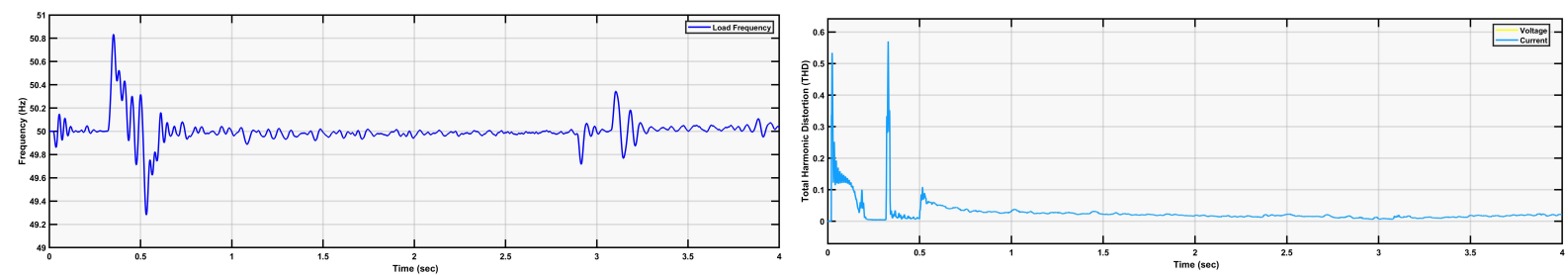

Figure 8: System frequency and Total Harmonic Distortion (THD) profile in load.

\subsubsection{Effect of Nonlinear Load:}

The simulation is also carried out using the induction motor as a load. Initially, an induction motor rating $4 \mathrm{~kW}$, with zero load torque, is taken with a resistive load of $4 \mathrm{~kW}$. At the moment of synchronization, the system has supplied the resistive load and induction motor with no load. At the simulation time of 2.0 sec, the induction motor load torque increases to full load, i.e., $26.7 \mathrm{~N}$-m. For observing the effect of irradiance 
variation on load sharing, at simulation time $2.5 \mathrm{sec}$, the irradiance level on SPV is reduced to $800 \mathrm{~W} / \mathrm{m} 2$ (Initially, 1000W.m2). The decrease of irradiance level, reduction of SV output compels the MHP to share more load as shown in figure 9 (a). The induction motor load torque is again reduced to zero at 3.0sec. Furthermore, the irradiance level again increased to $1000 \mathrm{~W} / \mathrm{m}^{2}$ to bring the system in normal condition at simulation time $3.5 \mathrm{sec}$. The application of the induction motor brings the oscillation of system frequency until it reaches to steady state. Due to the inductive nature of the induction motor, the voltage drop in load is relatively high, as can be seen in figure 9 (b). The increment in motor loading without any var compensating device would lead to voltage instability in the system. However, the frequency of the system has not deviated more than $\pm 2 \%$, ignoring the condition of synchronization as can be seen in figure 9 (a). A motor at complete load condition draws more resistive current than inductive current resulting in quick damping of oscillation as seen in the simulation time interval of 2.0 seconds to 3.0 seconds. Moreover, the load has not been affected by irradiance reduction as MHP has shared the supply. As a result, the sinusoidal voltage and current waveform with THD $1.5 \%$ have been obtained, which is less than $5 \%$ limits as mentioned earlier subsection (see figure 9 (b)). Therefore, the THD level reduces with the induction motor current/voltage approach reaching the steady-state level. Moreover, the THD level of current and voltage depends on the level of load shared by the SPV and MHP except for the synchronization, power angle reset condition, and load change condition.
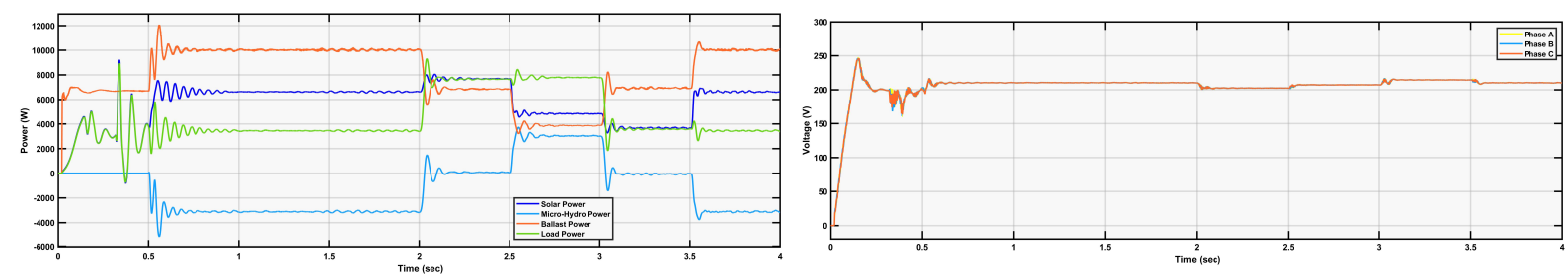

Figure 9: Load sharing and load voltage profile on the addition of induction motor as load. During addition of motor load, voltage sags slightly as can be seen in right side.
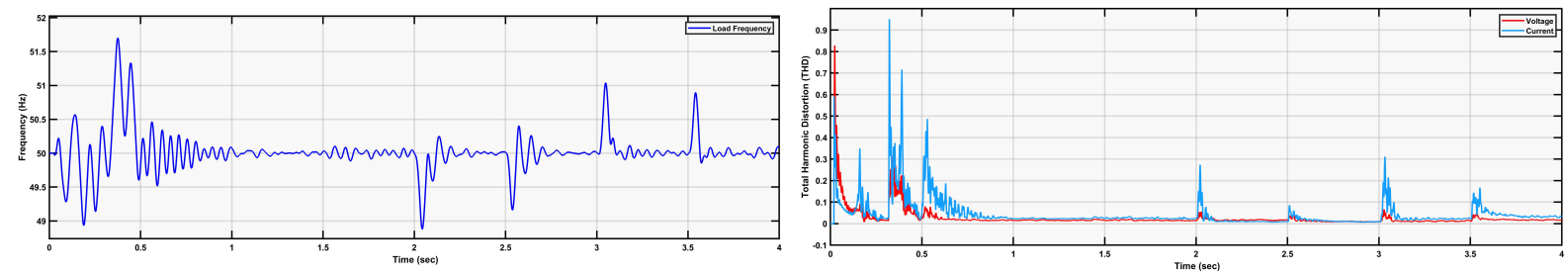

Figure 10: Frequency and Total Harmonic Distortion (THD) profile in load. The system's frequency oscillates for a short period before the motor becomes a steady state. Voltage harmonics are seen as high relative to current harmonics when the induction motor is in operation. 


\section{Conclusion and Future Work}

In this study, the dynamic model of the SV-based MHP hybrid system has been realized using the load sharing strategy of the power angle control method. In both load variation and irradiance variation scenarios, the system has a balanced frequency. The response load-sharing mechanism in both of the sources is observed. The application of induction motor load with a step-change in load torque concludes that the system can handle both linear and nonlinear loads with minimal frequency deviations for a short time. The synchronization can be easily obtained by resetting the virtual angle to the MHP voltage angle with added load angle for its step (sampling) time. The change in irradiance level doesn't show any frequency imbalance in the system through any complex frequency regulation mechanism that has not been used. Apart from transient time, the THD level of the load current and voltage for different scenarios remains within the short interval's standard limit. The grid interconnection of the hybrid system can be studied as further work. Moreover, improved SV can be integrated into the system to obtain better frequency regulation. The voltage stability of the hybrid system can be studied for the balanced voltage profile for different scenarios. Moreover, the study does not consider the voltage reference input for excitation. However, the use of inductive load on the system, which is generally happening in practical cases, causes the drop of system voltage significantly, hence the system's performance. Therefore, the appropriate voltage regulation can also be studied.

\section{Conflict of Interest}

The authors certify that they have no affiliations with or involvement in any organization or entity with any financial interest, or non-financial interest in the subject matter or study materials discussed in this manuscript.

\section{References}

[1] R. Syahputra, I. Soesanti, Renewable energy systems based on micro-hydro and solar photovoltaic for rural areas: A case study in yogyakarta, indonesia, Energy Reports 7 (2021) 472-490.

[2] S. Singh, R. K. Verma, A. K. Shakya, S. P. Singh, Frequency stability analysis of hybrid power system based on solar pv with smes unit, in: 2016 International Conference on Emerging Trends in Electrical Electronics \& Sustainable Energy Systems (ICETEESES), IEEE, 2016, pp. 5-11.

[3] M. R. Rahimpour, N. M. Kazerooni, M. Parhoudeh, Chapter 8 - water treatment by renewable energydriven membrane distillation, in: A. Basile, A. Cassano, A. Figoli (Eds.), Current Trends and Future Developments on (Bio-) Membranes, Elsevier, 2019, pp. 179-211. 
[4] S. Anaza, M. Abdulazeez, Y. Yisah, Y. Yusuf, B. Salawu, S. Momoh, Micro hydro-electric energy generation-an overview, American Journal of Engineering Research (AJER) 6 (2) (2017) 5-12.

[5] S. Murni, J. Whale, T. Urmee, J. Davis, D. Harries, The role of micro hydro power systems in remote rural electrification: a case study in the bawan valley, borneo, Procedia Engineering 49 (2012) 189-196.

[6] S. Maharjan, R. Shrestha, Technical problem analysis of micro hydro plants: A case study at pokhari chauri of kavre district, Journal of the Institute of Engineering 10 (1) (2014) 149-156.

[7] A. Razmjoo, R. Shirmohammadi, A. Davarpanah, F. Pourfayaz, A. Aslani, Stand-alone hybrid energy systems for remote area power generation, Energy reports 5 (2019) 231-241.

[8] K. Kusakana, J. Munda, A. Jimoh, Feasibility study of a hybrid pv-micro hydro system for rural electrification, in: AFRICON 2009, IEEE, 2009, pp. 1-5.

[9] J. Liu, D. Yang, W. Yao, R. Fang, H. Zhao, B. Wang, Pv-based virtual synchronous generator with variable inertia to enhance power system transient stability utilizing the energy storage system, Protection and Control of Modern Power Systems 2 (1) (2017) 1-8.

[10] K. M. Cheema, A comprehensive review of virtual synchronous generator, International Journal of Electrical Power \& Energy Systems 120 (2020) 106006.

[11] J. Liu, Y. Miura, T. Ise, Comparison of dynamic characteristics between virtual synchronous generator and droop control in inverter-based distributed generators, IEEE Transactions on Power Electronics 31 (5) (2015) 3600-3611.

[12] S. D'Arco, J. A. Suul, O. B. Fosso, A virtual synchronous machine implementation for distributed control of power converters in smartgrids, Electric Power Systems Research 122 (2015) 180-197.

[13] F. Bignucolo, R. Stecca, M. Coppo, Advantages of the virtual synchronous machine regulation for integrating low-inertia variable renewable generation in transmission systems, in: 2018 53rd International Universities Power Engineering Conference (UPEC), IEEE, 2018, pp. 1-6.

[14] K. Y. Yap, C. R. Sarimuthu, J. M.-Y. Lim, Virtual inertia-based inverters for mitigating frequency instability in grid-connected renewable energy system: A review, Applied Sciences 9 (24) (2019) 5300.

[15] Q.-C. Zhong, P.-L. Nguyen, Z. Ma, W. Sheng, Self-synchronized synchronverters: Inverters without a dedicated synchronization unit, IEEE Transactions on power electronics 29 (2) (2013) 617-630.

[16] M. Amin, M. Molinas, Self-synchronisation of wind farm in mmc-based hvdc system, in: 2016 IEEE Electrical Power and Energy Conference (EPEC), IEEE, 2016, pp. 1-6. 
[17] P. Chandrakar, S. Saha, P. Das, A. Singh, S. Debbarma, Grid integration of pv system using synchronverter, in: 2018 International Conference on Computation of Power, Energy, Information and Communication (ICCPEIC), IEEE, 2018, pp. 237-242.

[18] S. Meshram, G. Agnihotri, S. Gupta, Advanced photovoltaic/hydro hybrid renewable energy system for remote areas, Journal of Renewable and Sustainable Energy 6 (1) (2014) 013140.

[19] I. Cvetkovic, D. Boroyevich, R. Burgos, C. Li, M. Jaksic, P. Mattavelli, Modeling of a virtual synchronous machine-based grid-interface converter for renewable energy systems integration, in: 2014 IEEE 15th Workshop on Control and Modeling for Power Electronics (COMPEL), IEEE, 2014, pp. 1-7.

[20] R. Hesse, D. Turschner, H.-P. Beck, Micro grid stabilization using the virtual synchronous machine (visma), in: Proceedings of the International Conference on Renewable Energies and Power Quality (ICREPQ'09), Valencia, Spain, 2009, pp. 15-17.

[21] Y. Hirase, Y. Ohara, H. Bevrani, Virtual synchronous generator based frequency control in interconnected microgrids, Energy Reports 6 (2020) 97-103.

[22] G. M. Sarhan, A. P. D. A. M. Abdin, E. M. H. Shaalan, et al., Power angle control of virtual synchronous generator, Journal of Electrical Engineering 17 (2) (2017) 6-6.

[23] Q.-C. Zhong, G. Weiss, Synchronverters: Inverters that mimic synchronous generators, IEEE transactions on industrial electronics 58 (4) (2010) 1259-1267.

[24] Q.-C. Zhong, T. Hornik, Control of power inverters in renewable energy and smart grid integration, Vol. 97, John Wiley \& Sons, 2012.

[25] X. Ruan, X. Wang, D. Pan, D. Yang, W. Li, C. Bao, Design of lcl filter, in: Control Techniques for LCL-Type Grid-Connected Inverters, Springer, 2018, pp. 31-61.

[26] A. C. Kathiresan, J. PandiaRajan, A. Sivaprakash, T. Sudhakar Babu, M. Islam, et al., An adaptive feedforward phase locked loop for grid synchronization of renewable energy systems under wide frequency deviations, Sustainability 12 (17) (2020) 7048.

[27] M. Y. Allani, M. Jomaa, D. Mezghani, A. Mami, Modelling and simulation of the hybrid system pv-wind with matlab/simulink, in: 2018 9th International Renewable Energy Congress (IREC), IEEE, 2018, pp. $1-6$.

[28] W. Freitas, J. C. Vieira, A. Morelato, L. C. Da Silva, V. F. Da Costa, F. A. Lemos, Comparative analysis between synchronous and induction machines for distributed generation applications, IEEE transactions on Power Systems 21 (1) (2006) 301-311. 
[29] B. Singh, G. K. Kasal, S. Gairola, Power quality improvement in conventional electronic load controller for an isolated power generation, IEEE Transactions on Energy conversion 23 (3) (2008) 764-773.

[30] Ieee guide for synchronous generator modeling practices and parameter verification with applications in power system stability analyses (2020). doi:10.1109/IEEESTD.2020.9020274.

[31] M. H. Center, Synchronous machine si fundamental.

URL https://www . mathworks. com/help/physmod/sps/powersys/ref/synchronousmachinesifundamental.html

[32] I. W. Group, et al., Recommended practice for excitation system models for power system stability studies, IEEE Std 421.5-1992 (1992).

[33] W. G. P. Mover, E. Supply, Hydraulic turbine and turbine control models for system dynamic studies, IEEE Transactions on Power Systems 7 (1) (1992) 167-179.

[34] S. K. Rai, O. Rahi, S. Kumar, Implementation of electronic load controller for control of micro hydro power plant, in: 2015 International Conference on Energy Economics and Environment (ICEEE), IEEE, 2015 , pp. $1-6$.

[35] M. Elsavad, A. Sarhan, A. Abdin, Power angle control of virtual synchronous generator, Journal of Electrical Engineering 17 (2) (2017) 2.

[36] A. Vijayakumari, A. Devarajan, S. Mohanrajan, Power angle control of a single phase grid connected photovoltaic inverter for controlled power transfer, in: Proceedings of the International Conference on Soft Computing Systems, Springer, 2016, pp. 451-461.

[37] J. Svensson, Power angle control of grid-connected voltage source converter in a wind energy application (Dec 1995).

[38] M. D. Menon, A novel method to extract maximum power from solar panel of a grid connected phototvoltaic system using phase angle control and hysteresis current control, in: 2016 International Conference on Electrical, Electronics, and Optimization Techniques (ICEEOT), IEEE, 2016, pp. 3510-3516.

[39] R. Majumder, A. Ghosh, G. Ledwich, F. Zare, Angle droop versus frequency droop in a voltage source converter based autonomous microgrid, in: 2009 IEEE Power \& Energy Society General Meeting, IEEE, 2009, pp. 1-8.

[40] I. of Electrical, E. E. S. P. C. Committee, IEEE Guide for Harmonic Control and Reactive Compensation of Static Power Converters, Ieee, 1981. 